\title{
Entrevista com o colecionador de arte Adolpho Leirner
}

Luis Sandes

O concretismo paulista teve, na década de 1950 e no início da década de 1960, seu período de maior atuação. Foi um movimento artístico de vanguarda e seus artistas estiveram envolvidos em diversas polêmicas. Seguindo as propostas concretistas, os artistas produziam tanto obras de arte como alguns produtos funcionais, tais quais cartazes e projetos de jardins (Alexandre Wollner e Waldemar Cordeiro, respectivamente).

As obras de arte, à época, basicamente circulavam apenas entre seus próprios autores, que tinham na arte uma ocupação secundária. Eram funcionários de empresas, de bancos, entre outros, que trocavam entre si peças de arte. Foi o industrial Adolpho Leirner o primeiro colecionador a adquirir sistematicamente essas obras, a partir de 1961, como explica na conversa.

Nascido em São Paulo em 1935, Adolpho Leirner, como relata nessa entrevista de outubro de 2015, começou colecionando tapetes caucasianos. Além da coleção de arte concreta, formou, com sua esposa, Fulvia, uma coleção de art déco.

A família Leirner tem ligação antiga com as artes brasileiras. Isaí e Felícia Leirner, tios de Adolpho, ajudaram a fundar o Museu de Arte Moderna de São Paulo (MAM-SP). Nelson, filho desse casal, é artista. Sheila, sobrinha do colecionador, é crítica de arte. Jac, sua filha, é artista. A entrevista a seguir foi dada na residência do entrevistado.

\section{(Conversa sobre o designer Alexandre Wollner)}

Leirner: Não é de hoje que conheço essa figura, muito amigo. Ele fez a restruturação de nossa marca, empresa têxtil. Ele reformulou a marca, uma marca muito antiga, da década de 40 .

LS: Empresa familiar? 


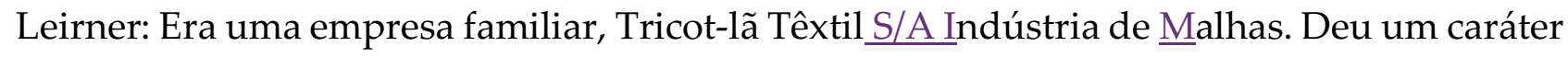
mais moderno para a marca. Poucas alterações e ficou muito interessante. Quem projetava nossos estandes na Fenit ${ }^{1}$, você não tinha nascido ainda...

LS: Nasci em 87.

Leirner: A Fenit era no Parque Ibirapuera. Ele fez uma linda cartela de cores.

LS: Deixa eu ver aqui. Primeiro eu queria que o senhor falasse da influência do concretismo na arte contemporânea, se existe, como ela é.

Leirner: Eu acho total, o construtivismo e o concretismo e arte geométrica têm uma influência enorme na arte contemporânea, a partir dos anos 70 eu diria, com alguns artistas minimalistas brasileiros, como o Waltércio [Caldas], Cildo [Meireles]. Eles tinham uma cabeça construtiva. Geométricas, com poucos traços, eu acho que continua tendo até hoje. Eu tenho uma filha artista, não sei se você sabe, a Jac. Ela também tem uma cabeça construtiva, ela bota as coisas sempre no lugar certo, bem colocadas, bem construídas. Agora a última série dela, fazendo uma série de sudoku. A última série dela expôs na Bienal de Sharjah, nos Emirados Árabes, super ordenada.

LS: Bacana isso, e décadas depois, não é? Quase um século depois...

Leirner: Bom, ela conviveu com isso na nossa casa, muitos anos.

LS: E algo que não começa só com os brasileiros, começa quase um século atrás, com Bauhaus, com...

Leirner: Ah, sim, um suprematismo russo, cem anos... O Maliévitch [Kazimir Maliévitch, artista russo, 1878-1935].

LS: Tá dando o que?

Leirner: Cem anos. 16, 17. É o meu papa.

LS: O senhor tem obra dele?

Leirner: Do Maliévitch? Rã! Eu gostaria de ter um print dele. O Maliévitch compra todos os museus do Brasil, uma obra dele. É fantástico. Pra mim, são os dois grandes artistas dos últimos cem anos, o Maliévitch e o Duchamp [Marcel Duchamp, artista francês, 1887-1968], são os dois grandes revolucionários dos últimos cem anos e por aí. Na verdade, depois do Maliévitch nós não aprendemos muito não, não só nós, mas mesmo os europeus, com o

\footnotetext{
${ }^{1}$ A Feira Nacional da Indústria Têxtil, que surge em 1958 e acontece até hoje. Até a década de 1970, teve grande peso na vida cultural da cidade, sendo palco de verdadeiros shows para os lançamentos ali realizados. 
Bauhaus e o De Stijl lá na Holanda. E a base foi toda dos suprematistas russos. E assim vai o mundo, um influenciando o outro.

LS: E como era o pessoal, como era o Waldemar Cordeiro?

Leirner: O Waldemar Cordeiro... É muito incrível. Eu nasci em Bom Retiro, nós tínhamos uma casa em frente ao Jardim da Luz. Olhando para o Parque da Luz, na rua Ribeiro de Lima, e a nossa casa tinha dois andares, nós morávamos embaixo, no primeiro andar morava o Waldemar Cordeiro. E a primeira pergunta que você me faz é justamente essa. A mulher do Waldemar Cordeiro me levava para passear de carrinho no parque. É isso.

LS: O senhor conheceu um pouquinho...

Leirner: Conheci muito. Mas é isso, depois ficamos anos sem nos ver, tinha o que... 3 anos. Mas conhecia a família.

LS: E mais tarde, como foi a relação com ele?

Leirner: Houve um distanciamento. Ele se dava muito bem com o Wollner e com o Geraldo de Barros. Ele faleceu muito cedo. Então eu não tive esse contato muito grande com ele. Eu sei que ele teve contato com minha mãe, um projeto de um jardim numa casa que nós temos na rua São Salvador, e não foi executado, acabou não sendo executado o projeto. Ele foi paisagista também, você conhece alguns projetos dele? Muito interessantes.

\section{$(\ldots)$}

LS: E o Mário Pedrosa, o senhor conheceu? O senhor conheceu algum desses críticos?

Leirner: O Geraldo Ferraz, não tive contato. Eu viajei muito moço para a Inglaterra, com 18 anos fiz meu curso de engenharia têxtil, e logo em seguida eu voltei, no final dos anos 50 e comecei a trabalhar de uma maneira muito intensa, não tinha tempo para nada, na verdade, trabalhava só. Depois me casei...

LS: Como tinha tempo para a arte?

Leirner: Sempre olhando, iniciei a minha coleção logo cedo, no meu casamento eu comecei a colecionar $\stackrel{2}{*}$..

LS: E começou o contato com os artistas?

Leirner: Eu não, comecei a minha coleção com tapetes caucasianos. Meu pai tinha um casal de amigos que frequentava a nossa casa, e eu sempre ouvia ele dar suas opiniões em relação

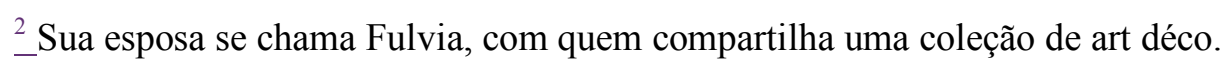

B.

RASILIANA- Journal for Brazilian Studies. Vol. 6, n.1 (December, 2017). ISSN 2245-4373. 
a tapetes caucasianos, me interessei muito, aprendi com eles. Porque eu sempre gostei de design. O curso de engenharia têxtil é todo também baseado em design, em cores e corantes, química, tingimento. Então isso me fez iniciar a minha coleção com tecido, que era o têxtil na época, então comecei com tapetes.

LS: E qual foi o pulo para a arte contemporânea?

Leirner: O pulo foi uma viagem para o Rio em 1961. Eu estava no hotel Copacabana Palace, trabalhando pela empresa, e, descendo do hotel, na avenida Nossa Senhora de Copacabana, eu atravessei a rua e na esquina vi um quadro vermelho na vitrine, duas linhas pretas e acabei comprando esse quadro porque eu adorei, porque eu achava que era um projeto arquitetônico ${ }^{3}$. E era um Milton Dacosta. Nem sabia quem era Milton Dacosta, não sabia nada, comprei o quadro e gostei.

LS: Aí começou a coleção de arte contemporânea.

Leirner: Só geométrica, e ao mesmo tempo baseada no têxtil. Eu comprei essa tapeçaria da Regina Graz, bem geométrica, bem concebida, essa tapeçaria que está atrás de você, absolutamente geométrica. E aí comecei a minha coleção de arte construtiva lentamente, logo depois adquiri obras do [Hélio] Oiticica, da Lygia Clark, o [Luiz] Sacilotto foi logo em seguida...

LS: Esses artistas você conviveu com eles?

Leirner: Eu só posso dizer que, até 1972, eu já tinha uns 65\% a 70\% da coleção construtiva que está no momento em Houston 4 .

LS: Foi muito rápido então.

Leirner: Foi. Foi em 10 anos que eu construí 70\% da coleção.

LS: Era trabalho e coleção.

Leirner: Eu gostava muito, conheci o Sacilotto, o Maurício Nogueira Lima...

LS: Como eram eles?

Leirner: Maurício é um lindo. Relação muito difícil colecionador e artista. Uma coisa...

LS: Por quê?

\footnotetext{
${ }^{3}$ Posteriormente o entrevistado confessou: "sou um arquiteto frustrado". A galeria era a Bercinski, na esquina com a rua Inhangá.

${ }^{4}$ Após ser oferecida para museus brasileiros, sua coleção foi vendida ao Museum of Fine Arts, de Houston, nos Estados Unidos, em 2007. 
Leirner: Os artistas tinham as obras como se fosse seus próprios filhos, eles não gostavam de vender, de se desfazer das obras...

LS: Mas eles cobravam preços altos...?

Leirner: Eles estavam completamente démodés, ninguém queria saber de construtivismo naquela época, porque já nesse período a abstração informal já era mais moda. A abstração informal já estava em voga e ninguém queria saber do outro, a abstração geométrica tinha artistas...

LS: Achavam que não tinha valor...

Leirner: Não havia mercado na época, e a produção deles foi muito pequena. Infelizmente hoje cresceu a produção deles através de obras não verdadeiras. Tem muita coisa adulterada no mercado, fica meio complicado.

LS: Muito mesmo?

Leirner: Tem aparecido muitas obras duvidosas.

LS: E tem gente qualificada a atestar?

Leirner: Eu já não quero me envolver com isso porque eu sei foi difícil para mim conseguir as minhas obras.

LS: Prefere se ausentar das polêmicas.

Leirner: Não é comigo, eu já tive muita polêmica com a venda da minha coleção, eu... e que foi oferecida para alguns museus aqui, se abstiveram e resolveram não... ${ }^{5}$

LS: Eles chegavam a argumentar alguma coisa?

Leirner: Simplesmente... uma coleção ninguém se interessava por isso, ninguém. Agora, uma coisa muito interessante que aconteceu. Em 78, a Aracy Amaral e o Ronaldo Brito organizaram uma exposição na Pinacoteca, sobre o projeto construtivo. Para mim foi de uma importância... Conhece? Eles reeditaram agora. Então para mim essa exposição foi um marco. Em 72 eu já tinha $60 \%$ da coleção. E me recordo muito bem, em 78 me requisitaram algumas obras, para que emprestassem para essa exposição. E eu não me considerava colecionador naquela época, mas, nesse momento, após essa requisição: "uma pessoa está pedindo obras da minha coleção para serem expostas em museus?". Aí minha vida mudou em relação ao termo colecionador, e aí me considerei um colecionador. Finalmente. Aí eu

\footnotetext{
${ }^{5}$ Ainda que não fosse uma coleção tombada e mesmo não havendo interesse de museus brasileiros na compra, algumas pessoas do meio cultural fizeram críticas à venda. 
preenchi os gaps, as faltas da coleção, fui preenchendo mais esses 30\%. E, mesmo após essa exposição maravilhosa na Pinacoteca, levou-se desde 78 até início de $90 . .$. nada aconteceu com o concretismo, com exceção de um ou dois artistas, Lygia Clark e Hélio Oiticica. Que eram mais conhecidos. E o interesse começou a aumentar. Até minha grande exposição em 98 lá no MAM, não houve possibilidade de se fazer nada com a abstração geométrica aqui no Brasil. Ninguém queria, e foi um esforço muito grande para que essa coleção fosse exibida, tanto no MAM em São Paulo, e no MAM do Rio e a partir daí teve esse boom de arte geométrica que nós temos no mundo todo. E um reconhecimento internacional em relação ao concretismo e neoconcretismo brasileiro. Não sei se isso... Mas meu contato foi com [Antônio] Maluf, [Luiz] Sacilotto, [Hermelindo] Fiaminghi, muito próximos. E o Fiaminghi inclusive fez alguns trabalhos de publicidade para nossa empresa também. E muitos deles projetaram também estampas para a nossa empresa. Eu reproduzi estampas do Maluf, do Cordeiro tecidos, do Fiaminghi, conhecia muito bem o [Hércules] Barsotti. Frequentavam minha casa, nós nos víamos de uma maneira intensa.

LS: Agora no MASP vai começar uma exposição de tecidos de concretistas ${ }^{6}$.

Leirner: Não, eles vão mostrar a coleção de vestidos da Rhodia.

LS: Isso, e aí vai ter alguns concretistas.

Leirner: Tenho certeza que meus vestidos vão estar lá também, porque, como te disse, o Maluf fazia esses vestidos para a Rhodia. Eu tinha uma relação com a Rhodia. Porque eu usava fios da Rhodia. E essa relação muito... Inclusive, o Wollner fez o projeto do nosso stand na Fenit, lá no Ibirapuera, onde o pavilhão da Rhodia era o highlight, eles faziam desfiles fantásticos.

LS: Alguns meses atrás, no Museu da Casa Brasileira, teve uma exposição, era Op-Art ${ }^{7}$ E tinha...

Leirner: Eu participei dessa exposição, não sei se você viu a minha participação...

LS: A sua participação? Deixa eu lembrar? Em que sentido?

Leirner: Eu tive uma vitrine inteira nossa da Tricot-lã, da minha empresa.

\footnotetext{
${ }^{6}$ Exposição “Arte na moda: Coleção MASP Rhodia”, de outubro de 2015 a fevereiro de 2016.

7 “Op-Art - Ilusões do Olhar”, no primeiro semestre de 2015.
} 
LS: Eu não sabia que era sua empresa, então não registrei... eu lembro de uma vitrine de vestidos...

Leirner: Uma vitrine de material publicitário, de logotipos da minha empresa e da minha paixão pelo op-art, com fotos do escritório, com obras do Vasarely atrás de mim. Já era apaixonado por isso. Emprestei algumas obras para essa instituição.

LS: Entendi. Uma coisa que me lembrei quando o senhor estava falando é que muito dos concretistas tinham alguma função profissional ligada a indústria...

Leirner: A publicidade, o Sacilotto trabalhava numa empresa que fabricava esquadrias metálicas, o Fiaminghi com publicidade. O Geraldo de Barros formou uma empresa de construção, uma empresa de mobiliário.

LS: E você acha que uma coisa...

Leirner: Eles não poderiam viver com a arte deles, entendeu?

LS: Você acha que uma coisa implicava a outra? O concretismo implicava a opção? Não estou sabendo me expressar direito, mas o senhor acha que havia uma conexão entre a profissão na indústria e o concretismo?

Leirner: Justamente com esses artistas, com o Sacilotto, já a geometria das esquadrias metálicas era evidente que deram influência também na obra dele. Do Fiaminghi, publicidade sem dúvida nenhuma. E do Maluf também, porque Maluf foi aquele projeto do Copan, do lado do Copan, no Ipiranga, o Maluf tem uma parede muito linda de azulejo, um desenho gráfico maravilhoso. Quer dizer, os artistas procuravam sobrevier de outras formas.

LS: E como era a relação, o senhor sabe dizer, a relação do concretismo com a abstração informal?

Leirner: Abstração informal veio contra o concretismo, isso foi um movimento contrário a tudo que era cabeça, e a abstração informal já era de dentro, espontâneo, etc.

LS: E o Volpi? O senhor chegou a conhecer?

Leirner: Conheci, almoçava na casa dele várias vezes. Aos sábados.

LS: Tomava vinho com ele?

Leirner: Gostoso. Com os volpistas, com Ladi [Biezus], [Marco Antônio] Mastrobuono, passava bons tempos, era gostoso.

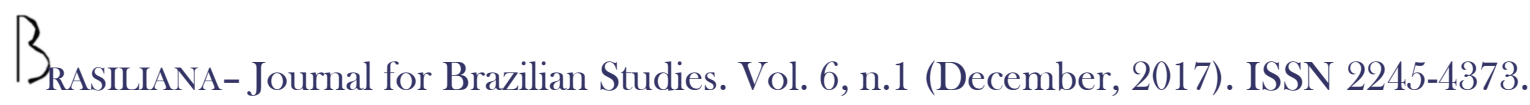




\section{LS: Como era a convivência lá?}

Leirner: Uma pessoa muito simples, sem frescuras, ele ficava lá. Muito gostoso. Foi uma época linda, mas é isso, comprei meu Volpi, as bandeirinhas verdes sobre rosa, uma peça muito importante da coleção, eu acho que 70... depois consegui uma obra tão importante do Mário Schenberg, que era um geométrico que era dele. Eu queria porque queria, eu acabei comprando... Tem uma obra do Volpi que ele tinha na coleção dele, eu acho que foi a obra mais cara que eu comprei na minha vida naquela época, eu não sei nem como eu paguei, meu Deus.

LS: O senhor ainda tem Volpi?

Leirner: Estão todos em Houston. Você conhece a minha coleção? Você tem o meu livro vermelho ${ }^{8}$ ?

LS: Não, eu estou com ele emprestado da biblioteca, um livro caro...

Leirner: Foi coordenado pela Aracy Amaral. Chamei a Aracy e fizemos esse livro aqui [em casa]. Durante um ano e meio trabalhamos aqui. Foi muito gratificante esse tempo da minha vida. Foi justamente quando a exposição foi lançada no MAM, dos 50 anos do MAM, você não chegou a ver, né?

LS: Não.

Leirner: Em 98. Depois foi para o Rio.

LS: E o senhor acha que o concretismo... qual foi a importância do Volpi para o concretismo? Leirner: Volpi participou durante um período da produção dele com obras absolutamente geniais, vai saber como ele fez, é meio complicado, é muito difícil a gente chegar a uma conclusão. Alguns dizem que ele era totalmente espontâneo, eu diria que não é o caso, a obra que... a abstração geométrica da minha coleção dá para se notar uma régua e um lápis delineando a pintura bem claramente. Hoje você vê uma sombrinha de lápis na obra. Ele usava essa régua e esse lápis, ele criou obras singelas assim, a bandeira, coisa absolutamente geométrica e matemática, às vezes, e ele usou isso de maneira fantástica. Eu tenho na coleção uma obra extremamente interessante, parece até um escultor, uma obra tridimensional, sai da tela. Impressionante, um traço do Volpi da década de 50.

\footnotetext{
${ }^{8}$ Amaral, Aracy (Org.). Arte Construtiva No Brasil: Coleção Adolpho Leirner. São Paulo: DBA, 1998.
} 


\section{LS: Bandeira? Mastro?}

Leirner: Nem bandeira, nem mastro, um elemento só que parece uma obra do Richard Serra atual. Ou do Ellsworth Kelly. Uma coisa fenomenal. Eu te mostro no meu livro depois do que se trata. Mas ele conviveu com Willys de Castro, com essa turma toda o Volpi, provavelmente esses concretos influenciaram o Volpi de uma forma ou de outra em um período muito pequeno da produção dele, mas foi brilhante esse período. Único.

LS: E ao mesmo tempo o senhor acha que foram os concretistas que colocaram o Volpi em primeiro plano, ou ele foi por conta própria?

Leirner: Em primeiro plano como? Como artista fantástico? Foi por conta própria, não era necessário apoio de ninguém, era um colorista fenomenal. Se ele não tivesse passado por esse período geométrico ele iria sozinho e sem dúvida nenhuma. Agora os concretistas, o Willys, o Barsotti, eles tinham uma certa influência no meio, no milieu crítico do período aqui, pode ser que deram uma mão para ele, mas... ele ia sozinho mesmo.

LS: Volpi é Volpi.

Leirner: Isso diz o Willys de Castro: Volpi é Volpi. Essa é uma afirmação do Willys.

LS: Que bom que não sou eu que estou dizendo. E uma coisa que eu li, mas vi nos dois sentidos, tem gente que fala que teve um atraso, mas tem gente que fala que teve um adiantamento da abstração no Brasil, tem gente que fala que chegou adiantado, tem gente que fala que chegou atrasado. O que o senhor acha?

Leirner: No Brasil? Chegou depois da Argentina. Chegou atrasado.

LS: Atrasado. Lá chegou na década...

Leirner: De 48.

LS: Com Maldonado.

Leirner: Chegou atrasado, bem depois, mas na Argentina também chegou atrasado.

LS: Com relação a que?

Leirner: Com relação ao movimento geométrico da década de 30. Na Europa também chegou atrasado em relação aos russos. E assim as coisas vão. Aos suprematistas. Ao Kandinsky, etc., etc. E assim vai.

LS: Tudo está atrasado. (risos) 
Leirner: Todo mundo atrasado... é o que eu sinto. Evidentemente nós temos artistas aqui concretos e neoconcretos excepcionais, e uma qualidade única. Volpi é um deles dentro desse período. Essa pequena fase dele, ele fez coisas lindas em meados de 50.

LS: Ainda mais para o senhor que é grande adorador do concretismo.

Leirner: Mas, foi lindo. Quer dizer, essa influência do Max Bill aqui, me recordo daquela exposição dele...

LS: Comecinho de 50, né?

Leirner: 51... E o próprio Wollner foi para a Europa. Ele foi lá pra Ulm, ele foi por causa do Geraldo de Barros. Geraldo de Barros não aceitou, ele não pode ir e mandou o Wollner. Geraldo também é uma figura maravilhosa, muito amigo de Geraldo.

LS: Como era o Geraldo?

Leirner: Lindo, pessoa fantástica. Gostoso. Ele trabalhava no Banco do Brasil, pra sobreviver. Ele era funcionário do Banco do Brasil. Sabia disso?

LS: Não.

$(\ldots)$

LS: O Almir Mavignier me respondeu por e-mail...

Leirner: Ele mora em Munique, se não me engano. Eu estive com ele... no apartamento dele...

LS: Mas foi uma entrevista bem curta que ele me deu, ele nem estava disposto a...

Leirner: O Almir Mavignier é uma pessoa muito fechada em relação ao Brasil, ele se isolou completamente do Brasil. Não sei, ele é um brilhante... se envolveu com a Alemanha e esqueceu um pouco da gente.

LS: Ele está lá há muitas décadas, né?

Leirner: Eu acho que ele teve uma relação com Wollner muito grande lá na escola de Ulm, se não me engano.

LS: Não lembro do Wollner ter falado disso.

Leirner: Não sei se ele fez escola de Ulm também, não me recordo, mas ele está há muitos anos lá, e ele esqueceu um pouco do Brasil na minha opinião. Acho que o Mavignier poderia ter nos ajudado mais durante toda essa estada que ele está tendo lá na Europa com nossos artistas brasileiras. Se isolou.

B Rasiliana- Journal for Brazilian Studies. Vol. 6, n.1 (December, 2017). ISSN 2245-4373. 
LS: São opções que as pessoas fazem...

Leirner: São opções. A obra dele é lindíssima, eu adoro. A produção gráfica dele é fantástica.

LS: Deixa voltar para as perguntas. E com a questão da crítica, critica e produção artística ser nas mesmas pessoas, o Waldemar Cordeiro produzir e também ser crítico, o Gullar ser crítico e produzir, os irmãos Campos, como era isso? Era uma novidade isso?

Leirner: Eles tinham que fazer alguma coisa... não podiam viver de arte. O Gullar era um crítico, era um milieu muito pequeno, eles tomavam conta do pedaço, todos queria aparecer.

LS: Mas o milieu modernista também era muito pequeno, né? Mas não tinha tanto isso, de os mesmos fazerem as mesmas...

Leirner: Era especificamente crítico. O Pedrosa nunca se meteu a pintar. Hoje o Ferreira Gullar está produzindo o trabalho, ele está vendendo, ele tem marchands que vendem obras dele, ele está no mercado. Incrível isso. Mesmo fazendo essa famosa obra, o poema enterrado e tal. É uma grande personalidade na arte brasileira, mas é meio gozado, ele está produzindo hoje e vendendo as obras dele no mercado que ele mesmo criticou. E criticou de uma maneira errada em relação ao Waldemar Cordeiro, inclusive ele pediu desculpas a ele. Agora, faz seis meses, publicamente, [admitiu] que ele foi errado com relação a esse embate paulistas e cariocas durante o período construtivista. Mas foi lindo, fez uma declaração de que não deveriam ter acontecido esses embates, entre ele e Waldemar Cordeiro.

LS: E falando nessa divisão paulistas e cariocas, sempre parece que os cariocas seriam mais, principalmente na divisão entre os neoconcretistas e os concretistas, que os cariocas seriam mais sensuais, menos teóricos.

Leirner: Sim, isso que aconteceu com o neoconcretismo. Eles acham que é por aí, mas é um fato. Eles tinham ideias mais amplas que os nossos concretistas, eram mais focados aqui na geometria, na matemática, mais racionais, nas cores. Foi isso que deu um sentido para esse movimento chamado neoconcreto. Agora a base desse movimento neoconcreto é sem dúvida o concretismo, inclusive lá no Rio. O Serpa, o próprio Oiticica, a própria Lygia Clark. Bom, Lygia Clark já é mineira, mas...

LS: Mas se estabeleceu lá.

Leirner: É, mas todas as obras anteriores, as obras sensuais e participativas desses artistas eram absolutamente concretas, tanto ou mais que os paulistas. É difícil separar isso.

ß 
LS: Justamente o que senhor falou, sensual no sentido de participação.

Leirner: Participação.

B RaSILIANA- Journal for Brazilian Studies. Vol. 6, n.1 (December, 2017). ISSN 2245-4373. 